\title{
Phytoprotection
}

phytoprotection

\section{Index des auteurs, volume 80 Author Index, Volume 80}

Volume 80, numéro 3, 1999

URI : https://id.erudit.org/iderudit/706193ar

DOI : https://doi.org/10.7202/706193ar

Aller au sommaire du numéro

Éditeur(s)

Société de protection des plantes du Québec (SPPQ)l

ISSN

0031-9511 (imprimé)

1710-1603 (numérique)

Découvrir la revue

Citer ce document

(1999). Index des auteurs, volume 80. Phytoprotection, 80(3), 195-196.

https://doi.org/10.7202/706193ar d'utilisation que vous pouvez consulter en ligne.

https://apropos.erudit.org/fr/usagers/politique-dutilisation/ 


\section{Index des auteurs, volume 80 Author Index, Volume 80}

\section{A-B}

Alt, P.J.

Appleby, J.E.

Arnason, J.T.

Arul, J.

Baird, R.E.

Banks, E.

Beaulieu, C.

Beaulieu, F.

Beckie, $\mathrm{H}$

Bélair, G.

Bélanger, A.

Bélanger, L. (Louis)

Bélanger, L. (Luc)

Belkahla, $\mathrm{H}$.

Benhamou, N.

Benoit, D.L.

Bernier, L.

Berthiaume, R.

Blais, R.

Boivin, $\mathrm{G}$.

Bostanian, N.J.

Bouchard, M.

Bourassa, J.-P.

Bourgeois, G.

Brisson, L.F.

Brodeur, J.

Brousseau, R.

Brown, A.

Bussières, G.

\section{C-D}

Chabot, R.

Chagnon, $\mathrm{M}$.

Charbonneau, F.

Charest, P.M.

Charpentier, G.

Chouinard, G.

Christie, B.R.

Coderre, D.

Collin, J.

Comeau, A.

Cormier, D.

Coulombe, C.

Coulombe, $F$.
Couture, L. $\quad 46$

Coux, F. 188

Daoust, G. $\quad 187$

35, 97 Desilets, $H$. 41

189, 190 Dessureault, M. 44

42 Dostaler, D. 45, 49

Dubois, D. 38

41 Dubuc, J.-P. 46

$45,47,50,51$

185

52,71

36, 190

42

E-J

Eudes, F.

185

189

169

44, 137

Fournier, F.

39, 192

Fréchette, B. 186

Frutos, R. 188

Gagnon, D. 189

Gagnon, S. $\quad 193$

36

39

191

44

39, 192

21

185

189

$37,192,193$

39,43

190

188

185

37,44

Gallant, C.E.

179

Germain, $H$. 39

Gilbert, M. 39

Goldansaz, S.H. $\quad 186$

Goodwin, S.B. $\quad 40,85$

Gotoechan, $\mathrm{H}$. $\quad 41$

Goyer, C. $\quad 45$

Hall, R. $\quad 41$

Hamelin, R.C. 39

Hébert, C. 185, 186, 191

Hervieux, V. 42

Hogue, R. $\quad 38,45$

Joannin R. $\quad 51$

\section{K-L}

Keita, S.M.

Kirouac, $M$.

188

$38,43,45,47$

Labrosse, I.

43

189

21, 193

Lacroix, M.

43,115

179

38, 186

Laflamme, $\mathrm{G}$.

$39,44,55$

44

169

188

46, 47

Lapierre, $\mathrm{H}$.

45

187

45

36 


\section{M-O}

Maheu, L.

Marchand, D.

Marineau, A.

Masson, L.

Maufette, $\mathrm{Y}$.

McNeil, J.N.

McRae, K.B.

Menzies, J.G.

Mercier, J.

Mongrain, D.

Morin, $Y$.

Morissette, $B$.

Morissette, $P$.

Morris, C.E.

Mottet, M.-J.

Mouton, J.-F.

Mullinix, B.G.

Omar, S.

Ouellet, F.

Ouellette, G.B.

\section{P-R}

Papadopoulos, J.

Paquet, M.

Paré, D.

Paré, J.

Parent, C.

Paulitz, T.C.

Peck, S.B.

Pelletier, L.

Peterkin, D.D.

Petit-Paly, G.

Peyronnet, $\mathrm{O}$.

Phillips, D.V.

Philogène, B.J.R.
Picard, K.

137

186,187

185, 186, 187, 192

179

13

65

46

193

192

192

51

46

186

1

190

47

37

48,49

$48,51,127$

187

187

103

39

188

1

190

Poliquin, A. 192

Poulin, J. 187

Préfontaine, G. $\quad 188$

Pronier, I. $\quad 48,49$

Racette, G. 21

Ramputh, A. 190

Rideau, M. 39

Rioux, D. $\quad 37$

Rioux, S. $\quad 45,49$

Rivest, S. 188

Rousseau, G. $\quad 49$

\section{S-Y}

Sagarra, L. 50, 103

Sallé, G. $\quad 48$

Schmith, J.-P. $\quad 42$

Schwartz, J.-L. 188

Scott, I.M.

Simard, L. 190

Simard, M. 37

Small, E.

Tellier, C. $\quad 50$

Tertuliano, M. 192

Thomas, P.L. 13

Toussaint, V. 51, 121

Tran, L.B. $\quad 188$

Tweddell, R. $\quad 42$

Vachon, V. 188

Villeneuve, S. 189

Vincent, C. $\quad 21,42,48,49,51$

Warwick, S.I. $\quad 52,71$

Wissocq, J.-C. $\quad 49$

Woods, S. 13

Yelle, S. 41 